\title{
FUNGSI DAN KEDUDUKAN BAHASA MANDARIN DI INDONESIA
}

\author{
Hermina Sutami
}

\begin{abstract}
Abstrak
Sejak bergulirnya Reformasi tahun 1998 Bahasa Mandarin dapat diibaratkan sebagai jamur yang tumbuh subur saat musim hujan. Secara tiba-tiba bahasa itu menjadi terkenal, menjadi bahasa asing kedua sesudah Bahasa Inggris yang paling "dicari-cari" oleh perusahaan. Mengingat kebutuhan di masyarakat kita, banyak kepala sekolah beranggapan Bahasa Mandarin perlu diajarkan, bukan hanya di SMA saja, bahkan mulai dari SD. Apakah para kepala sekolah sudah mengetahui bahwa negara kita mempunyai Kebijakan Bahasa Nasional yang mengatur pengajaran bahasa asing? Bila ketentuan Pemerintah dilanggar apa sanksinya? Bagaimana sosialisasi Pemerintah terhadap Kebijakan Bahasa yang dikeluarkannya agar sekolah mengetahui dengan jelas bahwa pelaksanaan pengajaran Bahasa Mandarin sudah sesuai dengan kebijakan yang digariskan Pemerintah? Mengapa di masyarakat timbul bermacam-macam persepsi tentang tujuan pengajaran bahasa ini? Apakah tujuan ini masih sama seperti 30 tahun ketika masih berdiri sekolah Cina/Tionghoa? Tujuan pengajaran Bahasa Mandarin berhubungan dengan kedudukan dan fungsi Bahasa Mandarin di Indonesia dewasa ini. Kedudukan dan fungsi Bahasa Mandarin, termasuk bahasa asing lainnya sudah diatur dalam Politik Bahasa Nasional dan Kebijakan Bahasa Nasional. Akan tetapi, dalam pelaksanaannya di masyarakat, mengapa berjalan seakan tanpa arah? Di mana peran Kemdikbud? Banyak keluhan mengenai tujuan pengajaran, bahan ajar, guru, dan kurikulum. Artikel ini berusaha memberi jalan keluar untuk mengatasi masalah yang terjadi dengan berpijak kepada Politik Bahasa Nasional dan Kebijakan Bahasa Nasional.
\end{abstract}

\section{Kata kunci}

Bahasa Mandarin, kedudukan, fungsi, Politik Bahasa Nasional, Kebijakan Bahasa Nasional

\begin{abstract}
Since Political Reformed in 1998, teaching of Mandarin language burst out everywhere. Many schoolsfrom primary until senior high school, even kindergarten - teach Mandarin. Having skill in Mandarin has become one prerequisite for new employees recruitment. In order to anticipate this situation, many schoolmasters without having understanding about our National Language Political Policy thought that Mandarin should be taught. They do not know that after nearly 30 years Mandarin was prohibited, the teaching Mandarin planning is really hard to be realised. There is no Mandarin language teacher, text book for Indonesian students, curriculum and syllabus, etc. In fact, many schools try to find old people who were educated in Chinese Schools before the era of late President Suharto to teach Mandarin. The result is far from what they expect. The Department of Education and Culture tried to overcome these problems, but there are still many problems facing us. This paper tried to show the problems, and gave suggesstion to overcome.
\end{abstract}

Keywords

Mandarin language, status, function, National Language Political Policy 


\section{PENGANTAR}

Setelah berlangsungnya Reformasi pada bulan Mei 1998, Bahasa Mandarin kembali diajarkan secara terbuka setelah sekitar 30 tahun dilarang. Dengan naiknya Gus Dur menjadi presiden RI tahun 2000 diterbitkan Keppres no.6 tahun 2000 tentang diperbolehkan orang Cina $^{1}$ menjalankan segala bentuk ekspresi kebudayaan Cina, termasuk mempelajari Bahasa Mandarin beserta aksaranya. Dengan adanya Keppres ini serta merta minat mempelajari Bahasa Mandarin tersalurkan secara terbuka² dalam bentuk formal, nonformal, dan informal.

Pengajaran itu dilaksanakan dalam bentuk kursus, les privat, pelatihan, pelajaran intra/ekstrakuriler, mata kuliah pilihan atau mata kuliah wajib di pelbagai program studi Cina perguruan tinggi di Indonesia. Sudah 14 tahun keadaan demikian berlangsung. Apakah pengajaran Bahasa Mandarin sudah dikembangkan dan ditata dengan baik atau malahan berjalan tanpa arah? Apa Pemerintah-Kementerian Pendidikan dan Kebudayaan - sudah menjalankan kebijakan mengenai Bahasa Mandarin sesuai Politik Bahasa dan Kebijakan Bahasa Nasional? Apakah tujuan pengajaran Bahasa Mandarin dewasa ini sama seperti saat belum dilarang tahun 1967? Apa sudah dilakukan sosialisasi Kebijakan Bahasa Nasional sehingga penyelenggara satuan pendidikan - baik formal maupun nonformal-memiliki arah yang jelas dan pasti dalam melaksanakan pengajaran bahasa ini? Apa strategi pemerintah menghadapi tuntutan pengadaan tenaga guru dan dosen Bahasa Mandarin di masyarakat? Apa manfaat kerja sama dengan pemerintah RRT di bidang ini bagi siswa, guru dan satuan penyelenggara pendidikan? Pertanyaan-pertanyaan di atas timbul karena banyak keresahan dan keluhan terhadap pelaksanaan pengajaran Bahasa Mandarin di Indonesia. ${ }^{3}$

Artikel ini berusaha menjawab pertanyaan di atas berlandaskan payung hukum dalam bahasa, yakni Politik Bahasa Nasional dan Kebijakan Bahasa Nasional. Politik Bahasa dan Kebijakan Bahasa Nasional harus menjadi acuan dalam kegiatan ajar mengajar Bahasa Mandarin di bumi Indonesia. Dengan demikian, institusi satuan pendidik penyelenggara pengajaran Bahasa Mandarin tidak berjalan tanpa arah. Yang

\footnotetext{
1 Kata Cina berpadanan dengan Tionghoa dan Tiongkok tanpa konotasi makna negatif apapun. Setelah Reformasi tahun 1989 kata cina seringkali diganti kata china yang dilafalkan dalam lafal Bahasa Inggris, sehingga kita jumpai orang China, negara China, bahasa China dalam koran berbahasa Indonesia. Hal ini tidak mendukung usaha Pemerintah melalui Badan Bahasa untuk menjadikan Bahasa Indonesia sebagai tuan rumah di negaranya sendiri. Secara tertulis, kata china mengandung gugus konsonan ch yang tidak ada dalam Bahasa Indonesia. Lalu timbul masalah bagaimana melafalkannya dalam Bahasa Indonesia [c'hina] atau apa?

${ }^{2}$ Semasa pemerintahan Suharto pengajaran Bahasa Mandarin diadakan secara diam-diam dalam bentuk kursus privat, di samping pengajaran Bahasa Mandarin secara resmi yang diakui pemerintah di FIBUI dan FS Universitas Darma Persada.

3 Informasi lengkap tentang pengajaran Bahasa Mandarin di Indonesia dapat dibaca pada surat yang dikirim oleh Dra. Inny C.Haryono kepada Atase Pendidikan Kedutaan Besar Republik Indonesia di Republik Rakyat Tiongkok (RRT) tertanggal 15 Juni 2012, nomor surat 179/DPP-APPBMI/VI/2012.
} 
tak kalah penting adalah konsistensi Pemerintah dalam menjalankan Kebijakan ini.

\section{POLITIK BAHASA NASIONAL DAN KEBIJAKAN BAHASA NASIONAL}

Negara kita sudah mempunyai aturan mengenai pembinaan, pengembangan, pembakuan dan pemeliharaan mengenai bahasa dan sastra yang mencakup Bahasa Indonesia, bahasa daerah dan pemakaian bahasa asing guna kepentingan nasional. Aturan itu tertuang dalam Politik Bahasa Nasional dan Kebijakan Bahasa Nasional.

Kerangka Politik Bahasa Nasional disusun atas dasar hasil Praseminar Politik Bahasa Nasional I tanggal 29-31 Oktober 1974 yang dilaksanakan di Jakarta, dan Seminar Politik Bahasa Nasional II pada 25-28 Februari 1975 yang juga dilaksanakan di Jakarta.

Tujuan akhir seminar kedua adalah pemanfaatan kebijaksanaan bahasa nasional sebagai alat untuk kepentingan pembangunan bangsa (Amran Halim 1984:12). Kebijakan tentang bahasa ini harus terencana, terarah dan terperinci agar fungsi serta pemakaian Bahasa Indonesia, bahasa daerah dan bahasa asing dapat diketahui secara tepat dan jelas. Kata "pemakaian" berhubungan dengan kedudukan sebuah bahasa. Amran Halim, Kepala Pusat Pembinaan Dan Pengembangan Bahasa Departemen Pendidikan Kebudayaan saat itu menyatakan pendapatnya (Amran Halim 1984: 13):

Pembedaan fungsi ini memungkinkan kita menempatkan bahasa-bahasa asing tertentu, terutama bahasa-bahasa Inggris, Belanda, Jerman, dan Prancis, pada kedudukan yang tidak lebih dari penggunaannya sebagai alat perhubungan antarbangsa, sebagai alat yang memungkinkan kita mengambil faedah dari kemajuan ilmu pengetahuan dan teknologi yang terdapat di negaranegara lain, dan sebagai salah satu sumber bahan untuk memperkaya bahasa nasional kita.

Melalui pernyataan di atas tampak jelas bahwa Politik Bahasa Nasional tidak hanya mengatur hal-hal yang berhubungan dengan Bahasa Indonesia dan bahasa daerah saja, melainkan mencakup bahasa-bahasa asing yang ada di Indonesia, tak terkecuali Bahasa Mandarin, sekalipun pada tahun 1975 pengajaran Bahasa Mandarin belum diperbolehkan. Dengan demikian, Politik Bahasa Nasional memiliki jangkauan masa depan yang jauh ke depan. Kebijakan bahasa apa pun yang akan diambil harus memperhatikan fungsi dan kedudukan bahasa yang dimaksud.

Hal itu mempunyai konsekuensi kepada para penyelenggara satuan pendidikan. Mereka harus memahami dengan jelas dan pasti alasan pengajaran Bahasa Mandarin di sekolah, kursus atau pelatihan yang dipimpinnya, bukan karena alasan ikut-ikutan, ngtrend, atau alasan lain yang tidak terdapat dalam Politik Bahasa Nasional.

Politik Bahasa Nasional diperkuat oleh Kebijakan Bahasa Nasional. Rumusan Kebijakan Bahasa Nasional didasarkan pada hasil Seminar Politik Bahasa tanggal 8-12 November 1999di Cisarua, Bogor. Kebijakan ini memberi perhatian khusus terhadap pengembangan pengajaran dan bahasa pengantar (Hasan Alwi 2003:8). Pengembangan pengajaran sangat relevan dengan pengajaran Bahasa Mandarin di Indonesia, karena bahasa ini sangat diminati oleh para kepala sekolah dari SD-bahkan taman kanak- 
kanak-sampai SMA untuk diajarkan kepada anak didiknya. Pertanyaannya, apakah pengajaran Bahasa Mandarin dilaksanakan sesuai selera kepala sekolah karena merasa bahasa itu sedang ngetrend? Kalau demikian, di mana gerangan Kebijakan Bahasa Nasional tentang pengajaran bahasa asing yang harus diketahui, ditaati dan dijalankan oleh satuan pendidikan? Apakah penyelenggara satuan pendidikan mengetahui Kebijakan Bahasa Nasional ini? Apakah Badan Bahasa-sebelumnya bernama Pusat Bahasa-sudah mensosialisasikannya?

Seminar Kebijakan Bahasa Nasional berlangsung setelah Reformasi 1998, pembahasan tentang Bahasa Mandarin tak terhindarkan. Masalah pengembangan pengajaran Bahasa Mandarin menjadi salah satu pokok pembahasan dalam Seminar itu karena merupakan aspek penting dalam pengajaran Bahasa Mandarin di Indonesia. Pengembangan pengajaran baru dapat dilaksanakan dengan benar bila kedudukan dan fungsi Bahasa Mandarin di Indonesia telah ditetapkan dengan tepat dan jelas. Setelah itu, baru dibuat rencana strategis pelaksanaan pengajarannya.

\section{KEDUDUKAN DAN FUNGSI BAHASA MANDARIN DI INDONESIA}

Untuk menentukan fungsi Bahasa Mandarin di Indonesia, harus diketahui lebih dahulu kedudukan bahasa itu. Kedudukan Bahasa Indonesia sebagai bahasa nasional tidak perlu dibahas lagi. Yang perlu dilakukan adalah memperjelas apa yang dimaksud "bahasa daerah" dan "bahasa asing", mengingat sejumlah warga keturunan Cina berpendapat Bahasa Mandarin merupakan bahasa daerah karena munculnya istilah Huazu atau 'suku Tionghoa' . Dengan hadirnya Huazu, warga keturunan Cina menganggap orang Cina di Indonesia juga menjadi salah satu suku di Indonesia seperti suku Jawa, Sunda, Menado, Dayak, dan sebagainya. Melalui definisi Hasan Alwi dan Dendy Sugono (2003: xii-xiv) tampak jelas kedudukan Bahasa Mandarin di Indonesia apakah termasuk bahasa daerah atau bahasa asing:

"Bahasa asing di Indonesia adalah semua bahasa, kecuali bahasa Indonesia, bahasa-bahasa daerah, dan bahasa rumpun Melayu."

Dua alasan lainnya,

"[...] karena bagaimanapun bahasa Cina secara genetis bukan bahasa yang tergolong ke dalam rumpun bahasa Austronesia, apalagi di kawasan Nusantara".

"Bahasa asing yang berfungsi sebagai bahasa ibu warga negara Indonesia kelompok etnis tertentu tetap berkedudukan sebagai bahasa asing".

Dengan demikian, kedudukan Bahasa Mandarin sama halnya seperti Bahasa Arab, Bahasa Belanda, Bahasa Inggris. Walaupun Bahasa Arab, Bahasa Belanda, Bahasa Mandarin merupakan bahasa ibu sebagian warga negara Indonesia keturunan Cina, 
Arab, Belanda, Inggris/Amerika, tetapi bahasa-bahasa itu tetap merupakan bahasa asing.

Setelah kedudukan Bahasa Mandarin ditetapkan dengan jelas, perlu dipertegas fungsinya. Kartono (1984:125) sependapat dengan Retmono (1984:133) mengatakan bahasa asing berfungsi sebagai alat komunikasi dengan bangsa lain guna membantu mempercepat proses pembangunan bangsa dan negara Indonesia. Bahasa-bahasa asing itu perlu dikuasai dengan tujuan untuk memanfaatkan ilmu dan teknologinya dalam menyikapi persaingan bebas di era globalisasi ini. Melalui penguasaan bahasa asing diharapkan terjadi pengalihan ilmu dan teknologi serta informasi lainnya dalam bahasa asing itu secara langsung, tanpa melalui terjemahan.

Melalui uraian di atas jelaslah fungsi pengajaran Bahasa Mandarin di Indonesia, bukan untuk "mencinakan" kembali warganegara Indonesia keturunan Cina seperti pada masa penjajahan Jepang (1942-1945) ${ }^{4}$. Bagaimana cara menyadarkan sekolah atau kursus yang mempunyai tujuan pengajaran seperti di atas? Bukankah Kementerian Pendidikan dan Kebudayaan harus secara berkesinambungan membimbing dan memantau jalannya pengajaran bahasa ini? Bila ada sekolah atau kursus yang "membandel", sanksi apa yang akan diberikan? Di sini perlu peran Dinas Pendidikan Kabupaten/Kota, karena para petugas dari Dinas Pendidikan ini langsung berhubungan dengan sekolah dan tempattempat kursus. Keputusan Kebijakan Bahasa Nasional tentang pengajaran Bahasa Mandarin hendaknya disebarluaskan kepada semua satuan pendidikan. Di samping itu di setiap kabupaten/kota dibentuk tim Musyawarah Guru Mata Pelajaran(MGMP) Bahasa Mandarin. Dinas Pendidikan setempat perlu memantau kegiatan tim MGMP Bahasa Mandarin agar tim ini tidak dimanfaatkan untuk kepentingan dan keuntungan pribadi atau negara asing.

Yang harus ditanamkan kepada masyarakat umum - baik penyelenggara satuan pendidikan maupun masyarakat awam - adalah Bahasa Mandarin merupakan bahasa asing. Pengajarannya bertujuan memajukan bangsa dalam menghadapi persaingan dunia yang semakin ketat. Jadi, kepentingan mengajarkan dan mempelajari Bahasa Mandarin adalah untuk kepentingan nasional Negara Kesatuan Republik Indonesia, bukan untuk kepentingan golongan keturunan Cina seperti pada zaman lampau.

Pembinaan dan pengembangan Bahasa Mandarin perlu dilakukan agar fungsinya sebagai bahasa asing dapat dilaksanakan. Pembinaan yang dimaksud adalah (Alwi dan Dendy 2003:9):

\footnotetext{
${ }^{4}$ Mulai 1 Agustus 1942 pemerintah Jepang hanya membolehkan sekolah berbahasa Indonesia dan bahasa Cina terus beroperasi. Semua anak Cina Peranakan yang sebelumnya bersekolah di HCS harus pindah ke sekolah berbahasa Mandarin. Penguasa Jepang memperlakukan Cina totok dan peranakan sebagai "sama-sama tak berharga dan memaksa agar organisasi mereka menjadi satu". Cina peranakan dianjurkan belajar Bahasa Mandarin (Suryadinata 1984:156).
} 
"Pembinaan bahasa adalah upaya untuk meningkatkan mutu pemakaian bahasa. Usaha-usaha pembinaan itu mencakup upaya peningkatan sikap, pengetahuan, dan keterampilan berbahasa yang dilakukan, antara lain, melalui pengajaran dan pemasyarakatan."

Dalam pembinaan tercakup kegiatan meningkatkan mutu pengajaran Bahasa Mandarin:

1) pengembangan kurikulum;

2) pengembangan bahan ajar yang sesuai kebutuhan siswa dan perkembangan metodologi pengajaran bahasa;

3) pengembangan tenaga pengajar Bahasa Mandarin yang profesional;

4) pengembangan sarana pengajaran Bahasa Mandarin yang memadai;

5) pemanfaatan teknologi informasi dalam Bahasa Mandarin.

Di samping membina, Bahasa Mandarin perlu dikembangkan. Definisi pengembangan (Alwi dan Dendy 2003: 13):

"upaya meningkatkan mutu bahasa agar dapat dipakai untuk berbagai keperluan dalam kehidupan masyarakat modern. Upaya pengembangan itu, antara lain, meliputi penelitian, pembakuan, dan pemeliharaan"

Dalam pengembangannya sebagai bahasa asing, perlu dilakukan penelitian yang memberi manfaat:

1) Mengembangkan metode pengajaran Bahasa Mandarin di Indonesia guna meningkatkan mutu pengajarannya.

2) Menyusun buku ajar yang sesuai dengan kebutuhan siswa Indonesia.

3) Melakukan penelitian terhadap masalah penguasaan bahasa di bidang leksikon, gramatika, fonologi, fonetik, semantik, pragmatik.

4) Meningkatkan kemampuan dan keterampilan mengajar para guru melalui pelatihan.

5) Mengembangkan teori pengajaran Bahasa Mandarin.

Pembakuan dan pemeliharaan Bahasa Mandarin tidak dilakukan karena Bahasa Mandarin merupakan bahasa asing.

Jika diurutkan terbalik, pembinaan dan pengembangan Bahasa Mandarin baru dapat dilakukan setelah fungsinya diketahui dengan jelas dan tepat. Untuk mengetahui fungsi, lebih dahulu ditetapkan kedudukannya: sebagai bahasa daerah atau bahasa asing. Langkah selanjutnya, menyusun rencana strategis pengajaran. Urutan tersebut dapat dilihat seperti di bawah ini.

Pembinaan dan pengembangan $\leftarrow$ fungsi $\leftarrow$ kedudukan $\leftarrow$ Politik Bahasa Nasional dan Kebijakan Bahasa Nasional 


\section{RENCANA STRATEGIS PENGAJARAN BAHASA MANDARIN DI INDONESIA}

Politik Bahasa Nasional dan Kebijakan Bahasa Nasional merupakan "payung hukum" yang menaungi semua kebijakan dalam pelaksanaan pengajaran Bahasa Mandarin. Kementerian Pendidikan dan Kebudayaan berkewajiban dan berkepentingan merealisasikannya ke semua lapisan pendidikan, dari tingkat formal seperti pendidikan menengah (sekolah menengah dan sekolah kejuruan) dan pendidikan tinggi (universitas, akademi), sampai tingkat nonformal, informal (kursus, pelatihan, dan sebagainya). Kemdikbud juga harus mensosialisasikan bahwa tujuan pengajaran Bahasa Mandarin dewasa ini tidak sama atau berbeda dengan 30 tahun lalu.

Pengajaran bahasa ini harusdiatur dan ditata, karena dalam pelaksanaan di lapangan ditemukan kasus-kasus yang tidak sesuai atau menyimpang. Hal itu membuat pengajaran Bahasa Mandarin berjalan sesuai selera kepala sekolah atau penyelenggara kursus, sehingga kebermanfaatannya dalam mentransfer ilmu dan teknologi asing menjadi sebuah pertanyaan besar.

Usulan rencana strategis ini didasarkan pada kondisi nyata dan kebutuhan siswa Indonesia saat ini, bukan didasarkan pada kondisi tahun 60-an ketika sekolah Cina masih berdiri. Pada masa lalu sekolah berbahasa Mandarin diperuntukkan bagi anakanak keturunan Cina. Dewasa ini pengajaran bahasa itu ditujukan kepada seluruh anak didik di Indonesia tanpa mempedulikan keturunan Cina atau bukan. Tujuannya sebagai alat komunikasi dalam alih ilmu dan teknologi dari negara-negara yang menggunakan Bahasa Mandarin dan aksara Han.

Kedudukan, fungsi, tujuan di atas disarikan berikut ini:

1) Bahasa Mandarin adalah bahasa asing.

2) Pengajaran Bahasa Mandarin dilaksanakan guna membangun bangsa dan negara Indonesia.

3) Pengajaran Bahasa Mandarin ditujukan kepada semua peserta didik di Indonesia.

4) Pengajaran Bahasa Mandarin dimanfaatkan dalam alih ilmu dan teknologi dari RRT, Taiwan, Singapura atau negara lainnya yang menggunakan Bahasa Mandarin.

5) Pengajaran Bahasa Mandarin harus memanfaatkan pakar linguistik Sinika Indonesia dan guru Bahasa Mandarin bangsa Indonesia.

Ada empat komponen dalam rencana strategis ini, yakni supervisi, kurikulum, guru dan bahan ajar.

\subsection{SUPERVISI}

Kemdikbud dibantu oleh badan-badan resmi pemerintah seperti Badan Standar Nasional Pendidikan (BSNP), Pusat Pengembangan dan Pemberdayaan Pendidik dan Tenaga Kependidikan Bahasa (P4TK Bahasa) bertugas memandu, mengawasi dan memantau pelaksanaan pengajaran Bahasa Mandarin di jenjang SMA/MA/SMK dan 
perguruan tinggi dari aspek kurikulum, guru dan bahan ajar. Pejabat berwenang di Kemdikbud beserta dirjen-nya yang berhubungan dengan pengajaran Bahasa Mandarin, P4TK Bahasa atau badan resmi lainnya harus seorang sarjana Sinologi lulusan universitas di Indonesia. Keharusan ini menjadi alasan utama karena mereka telah dididik secara ilmiah tentang Sinologi, seperti ilmu bahasa (linguistik) Bahasa Mandarin, budaya, sejarah, sastra, politik, filsafat, dan sebagainya. Dengan demikian, pejabat tersebut mengetahui dengan tepat dan jelas situasi pengajaran Bahasa Mandarin di Indonesia; apa yang dibutuhkan dan tidak dibutuhkan; langkah apa yang harus dan boleh dilakukan; langkah apa yang tidak boleh dilakukan. Semua kebijakan yang ditetapkan harus selalu berlandaskan Politik Pendidikan Nasional dan Kebijakan Bahasa Nasional.

Mengenai hal di atas, saya berharap Kemdikbud melibatkan pakar Sinologi lulusan Indonesia - bukan penutur Bahasa Mandarin yang mahir berbahasa Mandarin sebagai bahasa ibunya-dalam mengambil kebijakan yang berhubungan dengan pengajaran Bahasa Mandarin di Indonesia. Di Indonesia berdiri Universitas Indonesia yang memiliki Program Studi Cina sejak tahun 1954. Sejak berdirinya Jurusan Sinologi pada tahun itu sudah dihasilkan empat profesor, yakni Alm. Prof. Dr. Tjan Tjoe Som, Prof. Dr. Gondomono, Prof. Dr. A. Dahana dan saya sendiri. Di samping itu, dihasilkan pula beberapa doktor Sinologi. Dengan demikian, Kemdikbud dapat memanfaatkan tenaga para profesor dan doktor di atas, tak terkecuali doktor Sinologi dari universitas lain di Indonesia.

\subsection{KURIKULUM DANTINGKAT KEMAHIRAN}

Pada tahun 2011 Kemdikbud melalui BSNP melakukan perbaikan kurikulum nasional SMA/MA Bahasa Mandarin tahun 2004. Dalam kurikulum tersebut ditetapkan standar Bahasa Mandarin untuk SMA kelas pilihan, kelas bahasa dan MA.

Standardisasi Bahasa Mandarin di tingkat pendidikan nonformal dan informal dilakukan melalui Uji Kompetensi Bahasa Mandarin. Uji Kompetensi Bahasa Mandarin merupakan pengganti Ujian Nasional Bahasa Mandarin yang dianggap gagal. Uji Kompetensi dapat dijadikan tolok ukur kemahiran berbahasa asing seorang peserta didik kursus/pendidikan nonformal dan informal lainnya. Lembaga Sertifikasi Kompetensi Bahasa Mandarin Indonesia (LSKBMI) merupakan lembaga yang diakui dan dibina oleh Kemdikbud untuk menyelenggarakan Uji Kompetensi Bahasa Mandarin. Sertifikat kompetensi yang diterbitkan LSKBMI menunjukkan tingkat kemahiran yang sekaligus menjadi standar baku kemahiran Bahasa Mandarin di Indonesia yang belum tertata selama ini. LSKBMI dikelola oleh para akademisi yang berkualifikasi magister sampai profesor di bidang linguistik Sinika (linguistik Bahasa Mandarin), baik linguistik teoretis maupun linguistik terapan pengajaran bahasa.

Hal lain yang ditemukan pada universitas penyelenggara program studi Cina. Standardisasi program studi Cina di universitas-universitas di Indonesia belum 
dilaksanakan. Tidak heran bila ada program studi Cina memfokuskan diri pada bidang ekonomi atau bidang lainnya. Bagaimana pelaksanaan kurikulum wajib studi Cina yang sudah digariskan oleh Kemdikbud? Sekali lagi, peran Direktorat Pendidikan Tinggi Kemdikbud akan dipertanyakan jika ada program studi Cina memiliki kurikulum yang menyimpang dari Kebijakan Bahasa Nasional.

Melalui artikel ini disajikan standar tingkat kemahiran Bahasa Mandarin beserta kriterianya ${ }^{5}$.

\begin{tabular}{|c|l|l|l|}
\hline Nomor & Tingkat Kemahiran & Penguasaan Kata & Penguasaan Karakter Han \\
\hline 1 & Prakomunikatif 走进汉语 & $600-1000 \mathrm{kata} /$ 词 & 200-400 karakter Han/汉字 \\
\hline 2 & Komunikatif 初级汉语 & $1000-1500 \mathrm{kata} /$ 词 & $400-600$ karakter Han/ 汉字 \\
\hline 3 & Efektif 基础汉语 & $1500-2500 \mathrm{kata} /$ 词 & $600-1000$ karakter Han/ 汉字 \\
\hline 4 & Produktif 中级汉语 & $2500-3500 \mathrm{kata} /$ 词 & $1000-1750$ karakter Han/ 汉字 \\
\hline 5 & Selektif 高级汉语 & $3500-5000 \mathrm{kata} /$ 词 & $1750-3000$ karakter Han/ 汉字 \\
\hline
\end{tabular}

Tabel 1: lima tingkat kemahiran Bahasa Mandarin beserta penguasaan kata dan karakter Han

Tingkat Prakomunikatif merupakan tingkat terendah. Dalam pelaksanaannya, sebuah satuan pendidikan dimungkinkan membagi tingkat Prakomunikatif menjadi Prakomunikatif 1, 2; tingkat Komunikatif dibagi menjadi Komunikatif 1, 2. Hal itu dapat dilakukan sesuai jumlah jam belajar dari satuan pendidik.

Berdasarkan kelaziman dunia internasional, kriteria yang digunakan dalam menentukan tingkat kemahiran adalah jumlah kata dan karakter Han yang dikuasai. Dua aspek itu dihubungkan dengan kemampuan bekerja. Misalnya, orang yang berada pada tingkat Prakomunikatif dan Komunikatif, keduanya dapat bekerja sebagai juru ketik. Hanya saja kemampuan mengetik orang pada tingkat Komunikatif lebih tinggi daripada tingkat Prakomunikatif karena penguasaan kata dan karakter Han-nya lebih banyak. Tingkat Efektif dan Produktif setara dengan kemahiran mahasiswa program studi Cina tahun 3 dan 4. Penguasaan Bahasa Mandarinnya masih bersifat umum, sedangkan penguasaan Bahasa Mandarin tingkat Selektif berada di bidang khusus atau spesialisasi seperti akupuntur, sekretaris, pemandu wisata, bisnis, dan lain-lain.

Berdasarkan ketentuan Pemerintah, pengajaran Bahasa Mandarin di bidang pendidikan menengah (SMA/MA/SMK) dan tinggi (universitas, akademi) terdiri dari beberapa jenis pendidikan.

5 Tingkat kemahiran ini mengikuti ketentuan dari LSKBMI dalam melaksanakan Uji Kompetensi Bahasa Mandarin. 


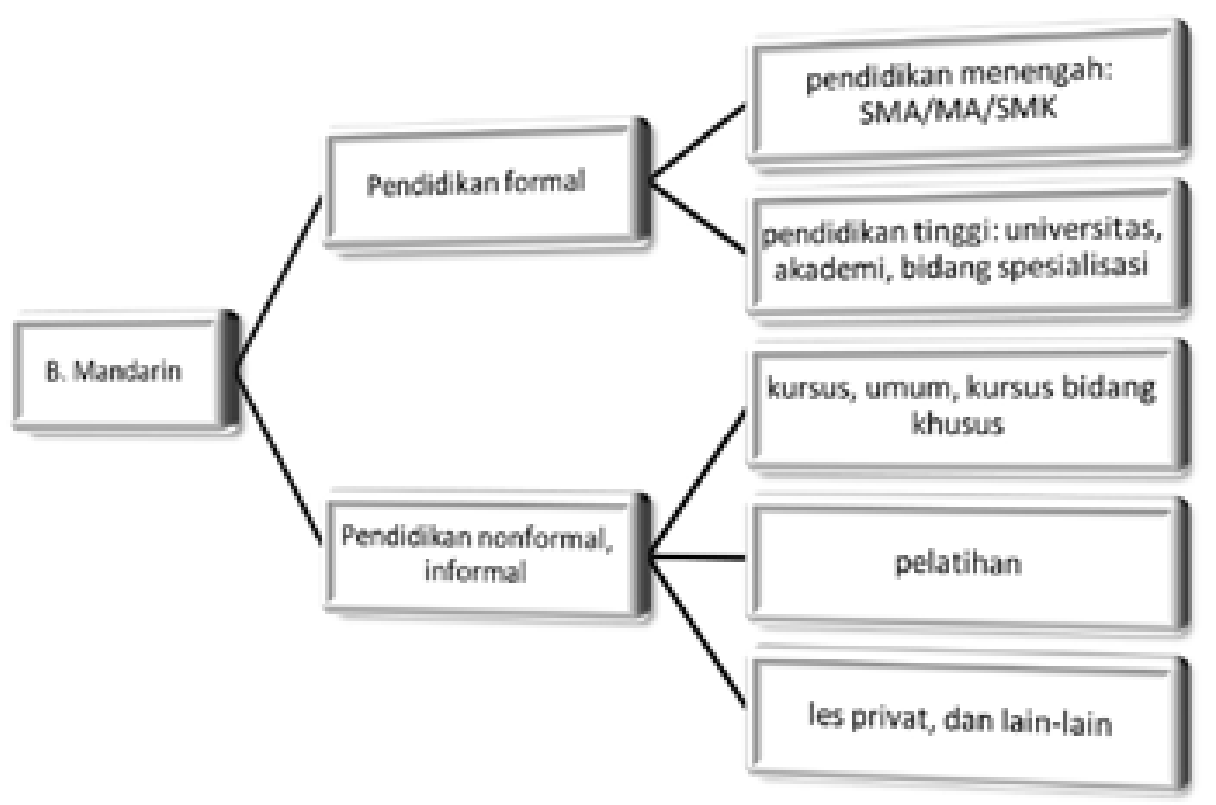

Perbandingan tingkat kemahiran dengan jenis pendidikan

\begin{tabular}{|c|c|c|c|c|c|c|c|c|c|c|}
\hline \multicolumn{6}{|c|}{ Pendidikan Menengah } & \multicolumn{4}{|c|}{$\begin{array}{l}\text { Pendidikan Tinggi (universitas, akademi) } \\
\text { program studi Cina }\end{array}$} & $\begin{array}{l}\text { Spesiali- } \\
\text { sasi }\end{array}$ \\
\hline \multicolumn{3}{|c|}{ Nonformal } & \multicolumn{3}{|c|}{ Formal } & Tahun 1 & Tahun 2 & Tahun 3 & Tahun 4 & \multirow{3}{*}{$\begin{array}{l}\text { Bidang } \\
\text { teknis/ } \\
\text { spesialis }\end{array}$} \\
\hline \multirow{2}{*}{$\begin{array}{c}\text { Kur- } \\
\text { sus }\end{array}$} & \multirow{2}{*}{$\begin{array}{l}\text { Pela- } \\
\text { tihan }\end{array}$} & \multirow{2}{*}{$\begin{array}{l}\text { dan } \\
\text { lain- } \\
\text { lain }\end{array}$} & \multicolumn{2}{|c|}{ SMU/MA } & \multirow{2}{*}{$\begin{array}{c}\text { SMK } \\
\text { (topik } \\
\text { khusus) }\end{array}$} & \multirow{2}{*}{$\begin{array}{l}\text { Bidang } \\
\text { nonteknis/ } \\
\text { spesia- } \\
\text { lis }\end{array}$} & \multirow{2}{*}{$\begin{array}{l}\text { Bidang } \\
\text { nonteknis/ } \\
\text { spesia- } \\
\text { lis }\end{array}$} & \multirow{2}{*}{$\begin{array}{l}\text { Bidang } \\
\text { nontek- } \\
\text { nis/spe- } \\
\text { sialis }\end{array}$} & \multirow{2}{*}{$\begin{array}{l}\text { Bidang } \\
\text { nonteknis/ } \\
\text { spesia- } \\
\text { lis }\end{array}$} & \\
\hline & & & $\begin{array}{l}\text { Pilihan } \\
\text { (topik } \\
\text { umum) }\end{array}$ & $\begin{array}{c}\text { Bahasa } \\
\text { (topik } \\
\text { umum } \\
\text { yang lebih } \\
\text { dalam) }\end{array}$ & & & & & & \\
\hline \multicolumn{3}{|c|}{$\begin{array}{c}\text { Prakomunikatif } \\
\text { 走进汉语 }\end{array}$} & $\begin{array}{l}\text { Prakomu- } \\
\text { nikatif } \\
\text { 走进汉语 } \\
\end{array}$ & $\begin{array}{l}\text { Prakomu- } \\
\text { nikatif } \\
\text { 走进汉语 } \\
\end{array}$ & $\begin{array}{l}\text { Prakomu- } \\
\text { nikatif } \\
\text { 走进汉语 } \\
\end{array}$ & $\begin{array}{l}\text { Prakomu- } \\
\text { nikatif } \\
\text { 走进汉语 }\end{array}$ & $\begin{array}{l}\text { Komuni- } \\
\text { katif } \\
\text { 初级汉语 }\end{array}$ & $\begin{array}{c}\text { Efektif } \\
\text { 基础汉语 }\end{array}$ & $\begin{array}{l}\text { Produktif } \\
\text { 中级汉语 }\end{array}$ & $\begin{array}{l}\text { Selektif } \\
\text { 高级汉语 }\end{array}$ \\
\hline \multicolumn{3}{|c|}{$\begin{array}{l}\text { 600-1000 kata/ 词, } \\
\text { 200-400 k. Han/ 汉字 }\end{array}$} & $\begin{array}{l}\text { 600-1000 } \\
\text { kata/ 词, } \\
\text { 200-400 k. } \\
\text { Han/ 汉字 }\end{array}$ & $\begin{array}{l}\text { 600-1000 } \\
\text { kata/ 词, } \\
\text { 200-400 } \\
\text { k.Han/汉 } \\
\text { 字 }\end{array}$ & $\begin{array}{l}\text { 600-1000 } \\
\text { kata/ 词, } \\
\text { 200-400 k. } \\
\text { Han/ 汉字 }\end{array}$ & $\begin{array}{l}600-1000 \\
\text { kata/ 词, } \\
\\
200-400 \\
\text { k.Han/ 汉 } \\
\text { 字 }\end{array}$ & $\begin{array}{l}1000-1500 \\
\text { kata/ 词, } \\
400-600 \mathrm{k} . \\
\text { Han/汉字 }\end{array}$ & $\begin{array}{l}1500- \\
2500 \\
\text { kata/ 词, } \\
600-1000 \\
\text { k. Han/ } \\
\text { 汉字 }\end{array}$ & $\begin{array}{l}2500-3500 \\
\text { kata/ 词, } \\
1000-1750 \\
\text { k. Han/汉 } \\
\text { 字 }\end{array}$ & $\begin{array}{l}3500- \\
5000 \\
\text { kata/ 词, } \\
1750- \\
3000 \mathrm{k} . \\
\mathrm{Han} / \text { 汉 } \\
\text { 字 }\end{array}$ \\
\hline
\end{tabular}

Bagan 2. Tabel perbandingan tingkat kemahiran dengan jenis pendidikan

Jumlah kata dan karakter Han yang tertera pada tabel di atas merupakan jumlah keseluruhan yang dikuasai peserta didik pada akhir jenjang pendidikan bagi yang mulai belajar Bahasa Mandarin dari nol. Pendidikan menengah terdiri dari pendidikan menengah formal (SMA/MA/SMK) dan nonformal (kursus, pelatihan, dan sebagainya). Tingkat kemahiran yang dicapai berada pada jenjang Prakomunikatif 走进汉语. Penentuan itu didasarkan pada jumlah jam belajar sekitar 180 jam selama tiga tahun belajar untuk SMA/MA/SMK, termasuk kursus atau pelatihan. 
Pada pendidikan tinggi (universitas, akademi) pencapaian tingkat kemahiran dimulai dari yang paling rendah (Prakomunikatif 走进汉语) pada tahun 1. Pengulangan di tingkat Prakomunikatif 走进汉语 dilakukan karena tidak semua mahasiswa di tahun pertama mendapat pelajaran Bahasa Mandarin di sekolah menengah. Dari tahun kedua sampai tahun keempat, setiap tahun terdapat peningkatan penguasaan kata dan karakter Han yang cukup banyak. Pada tahun kedua tingkat yang dicapai adalah Komunikatif 初 级汉语, tahun ketiga tingkat Efektif 基础汉语. Pada tahun terakhir di universitas dapat dicapai tingkat Produktif 中级汉语. Bagi yang berminat belajar di bidang khusus seperti kedokteran Cina, pengobatan Cina, bidang teknik, bidang ekonomi, dan sebagainya, kemahiran Bahasa Mandarinnya harus berada di atas tingkat Produktif, yaitu tingkat Selektif 高级汉语.

Pembelajaran Bahasa Mandarin di sekolah menengah atas dewasa ini merupakan persiapan untuk memasuki jenjang pendidikan yang lebih tinggi, tetapi tidak merupakan dasar untuk tingkat Komunikatif/初级汉语 di perguruan tinggi. Hal itu disebabkan karena pengajaran Bahasa Mandarin yang variatif di sekolah-sekolah menengah di Indonesia: ada sekolah yang menjadikan Bahasa Mandarin sebagai salah satu mata pelajaran wajib lulus (intrakurikuler); ada sekolah yang hanya menjadikan Bahasa Mandarin sebagai mata pelajaran tidak wajib (ekstrakurikuler). Di daerah tertentu seperti pulau Batam, Pontianak, Singkawang, Medan dan beberapa kota lainnya tingkat kemahiran Bahasa Mandarin siswa jauh lebih tinggi dari pada daerah lainnya. Hal ini tidak mengherankan karena Bahasa Mandarin merupakan bahasa komunikasi sehari-hari di daerah tersebut.

Dengan adanya perbedaan tingkat kemahiran di sekolah-sekolah menengah atas, Pemerintah perlu berdiskusi dengan para pakar linguistik Sinika-baik linguistik teoretis maupun pengajaran bahasa - untuk mengatasi masalah ini. Keberadaan Bahasa Mandarin yang beragam ini menjadi dasar untuk menetapkan pengajaran Bahasa Mandarin di tahun pertama perguruan tinggi dewasa ini tidak berada pada tingkat Komunikatif 初级汉, tetapi tetap di Prakomunikatif/走进汉语. Kesinambungan pengajaran di SMA/MA/SMK ke perguruan tinggi/akademi menjadi masalah tersendiri bagi pengajaran bahasa asing di Indonesia. Pemerintah harus berpikir secara holistis-dari pendidikan menengah sampai pendidikan tinggi-untuk mengatasi masalah di atas.

\subsection{GURU}

Hal yang memprihatinkan adalah kurangnya tenaga guru dan dosen Bahasa Mandarin di sekolah dan perguruan tinggi. Bantuan tenaga guru atau dosen dari RRT tidak boleh menyaingi atau mematikan mata pencaharian dan kreativitas guru dan dosen Indonesia. Pemerintah harus melindungi kepentingan guru Indonesia. Guru asing tidak diberi fasilitas yang berlebihan sehingga terjadi diskriminasi antara guru Indonesia dan guru asing dari segi finansial, perlakuan, fasilitas, dan sebagainya. Pemerintah harus 
menetapkan dan menjalankan secara ketat tingkat pendidikan dan kualifikasi guru bantu. Pemanfaatan tenaga guru harus mendahulukan kepentingan guru WNI, bukan sebaliknya. Hal yang harus disadarkan kepada satuan pendidik atau sekolah adalah bahwa pendidikan bukan tempat mencari keuntungan finansial, melainkan untuk mencerdaskan dan memajukan bangsa Indonesia.

Dewasa ini orang yang disebut "guru" beraneka ragam. Pemerintah perlu menyelesaikan masalah kualifikasi mereka. Sesuai ketentuan Pemerintah, guru harus berijazah S1. Tetapi tuntutan ini belum dipenuhi mengingat belum ada universitas yang khusus menghasilkan guru Bahasa Mandarin. Oleh karena itu, Pemerintah perlu mendukung dan memfasilitasi didirikan universitas penghasil guru SMA/MA/SMK.

Apa yang dilakukan terhadap guru yang ada sekarang ini? Pemerintah harus mengadakan program pendidikan pengajaran Bahasa Mandarin khusus bagi guru yang belum berijazah S1 agar mereka mencapai kualifikasi setaraf S1.

Bagaimana dengan guru bantu dari RRT? Sesuaikah pengeluaran finansial sekolah dengan manfaat yang diperoleh? Penggunaan guru bantu tersebut apakah bukan semata-mata untuk menaikkan gengsi sekolah karena mampu menggaji guru orang Cina "asli". Bagaimana implementasi Kebijakan Bahasa Nasional mengenai guru bantu dari RRT dan guru Indonesia sendiri? Sejumlah pertanyaan muncul di masyarakat mengenai guru bantu dan peningkatan kemampuan guru Indonesia. Ini merupakan masalah serius yang perlu dipecahkan dengan melibatkan pakar Sinologi.

Ada beberapa hal yang patut dipertimbangkan. Apakah keadaan pengajaran Bahasa Mandarin di Indonesia sudah begitu mendesak sehingga perlu mendatangkan guru bantu dari RRT? Jika memang diperlukan, harus dibuat persyaratan akademis dan ketentuan finansial terhadap guru bantu yang tidak merendahkan guru Indonesia. Apa makna istilah "guru bantu"? Apakah sekolah harus mengeluarkan dana khusus untuk guru bantu? Semua persyaratan kerja guru bantu harus sesuai dengan ketentuan Pemerintah tentang tenaga kerja asing di Indonesia. Dana yang dikeluarkan untuk guru bantu tidak boleh melebihi gaji guru Indonesia. Kemdikbud berhak mengeluarkan standar gaji dan tunjangan bagi guru asing yang tidak boleh melebihi standar gaji guru Indonesia.

Kebijakan apapun yang ditetapkan harus melindungi guru Indonesia. Pemerintah sudah saatnya mendirikan universitas pendidikan yang menghasilkan guru Bahasa Mandarin tanpa perlu mendatangkan guru bantu dari RRT.

\subsection{BAHAN AJAR}

Pada tahun 2010 melalui kerja sama antara BSNP dan Pusat Kurikulum dan Perbukuan juga telah dihasilkan instrumen penulisan buku ajar Bahasa Mandarin.Instrumen ini digunakan oleh para penulis buku ajar untuk menulis buku ajar Bahasa Mandarin tingkat SMA/MA. Pencapaian dua komponen di atas menunjukkan kinerja yang baik dari Kemdikbud dan BSNP, walaupun masih perlu dilakukan pembenahan di sana-sini. 
Beberapa hal yang harus diperhatikan tentang buku ajar. Banyak penulis Indonesia menulis buku pelajaran Bahasa Mandarin, tetapi buku-buku tersebut belum layak digunakan di SMA/MA/SMK. Kekurangannya dalam hal: kebakuan Bahasa Mandarin, kebakuan Bahasa Indonesia, sistem ejaan Hanyu Pinyin yang tidak betul, istilah gramatika yang baku dalam Bahasa Indonesia, pengetahuan teoretis penulis mengenai tata bahasa Mandarin tidak memadai. Untuk mengatasi hal ini, Pemerintah sudah mengambil langkah yang diuraikan pada paragraf pertama subbab ini. Saran kepada Pusat Kurikulum dan Perbukuan adalah agar mengadakan pelatihan penulisan buku ajar Bahasa Mandarin berdasarkan instrumen yang disusun BSNP kepada para calon penulis buku ajar. Dengan adanya tuntunan, bimbingan dan pengarahan, dipastikan mutu buku yang disusun akan lebih baik dibandingkan saat ini (tanpa pelatihan menulis buku ajar).

Bahan ajar hendaknya mencerminkan kebutuhan pembelajar Indonesia dewasa ini, bercirikan budaya nasional Indonesia walaupun mengajarkan juga budaya Cina. Pengadaan buku ajar tidak boleh bermotif bisnis, terlebih lagi mengharuskan pemakaiannya tanpa seizin BSNP dan Pusat Kurikulum dan Perbukuan. Buku ajar yang digunakan di sekolah-sekolah Indonesia harus dicetak dan diterbitkan oleh pencetak dan penerbit Indonesia di wilayah NKRI. Penulis buku ajar adalah orang Indonesia; bila menggunakan jasa tenaga asing, tenaga tersebut hanya sebagai mitra kerja (konsultan), bukan pengarang. Dengan cara demikian, kita akan meningkatkan kualitas guru Indonesia dalam mengajar dan menulis buku ajar.

Dewasa ini banyak SMA/SMK digunakan buku ajar yang ditulis oleh penulis utama dari RRT, dicetak dan diterbitkan di RRT. Buku itu sudah digunakan di Indonesia tanpa persetujuan BSNP dan Pusat Kurikulum dan Perbukuan sebagai badan yang berwenang menentukan layak pakai sebuah buku ajar. Di sini timbul pertanyaan, apakah hal itu diketahui dan diijinkan oleh Dirjen Pendidikan Dasar dan Menengah? Mengapa terjadi hal di atas?

\section{KESIMPULAN}

Menghidupkan kembali pengajaran Bahasa Mandarin sejak 1989 belum menunjukkan peran maksimal Kemdikbud melaksanakan Politik Bahasa Nasional dan Kebijakan Bahasa Nasional. Hal itu dapat dipantau dengan adanya pengajaran Bahasa Mandarin sejak SD, bahkan di TK, apalagi akhir-akhir ini muncul "Sekolah tiga Bahasa (Inggris, Mandarin, Indonesia)".

Kebutuhan mendesak yang harus dilakukan pemerintah adalah "mencetak" guru Bahasa Mandarin. Caranya, bukan mendatangkan guru bantu dari RRT, tetapi "mencetak" guru Bahasa Mandarin yang berkewarganegaraan Indonesia serta meningkatkan mutu guru yang sudah ada. 
Penyusunan buku ajar Bahasa Mandarin harus dikoordinasikan oleh Pusat Kurikulum dan Perbukuan dengan mengadakan pelatihan penulisan buku ajar kepada para penulis buku ajar berkewarganegaraan Indonesia. Buku ajar yang dihasilkan harus dicetak di wilayah NKRI.

Kemdikbud perlu bekerja sama dengan pakar linguistik Sinika (teoretis dan terapan-pengajaran bahasa) Indonesia dalam membuat kurikulum, bahan ajar, peningkatan mutu guru, pendirian universitas pendidikan Bahasa Mandarin, karena pakar Indonesia-bukan pakar asing-yang paling mengetahui situasi dan kondisi di Indonesia. Tidak ada diskriminasi antara guru asing dan guru Indonesia dalam hal fasilitas, honor, perlakuan, dan sebagainya.

\section{KEPUSTAKAAN}

Halim, Amran (ed.). Politik Bahasa Nasional I. Pusat Pembinaan dan Pengembangan Bahasa Departemen Pendidikan dan Kebudayaan. 1976.

(ed.). Politik Bahasa Nasional 2. Pusat Pembinaan dan Pengembangan Bahasa Departemen Pendidikan dan Kebudayaan. 1984.

Alwi, Hasan dan Dendy Sugono. Politik Bahasa: Rumusan Seminar Politik Bahasa. Jakarta: Pusat Bahasa. 2003.

Halim, Amran. "Fungsi Politik Bahasa Nasional" dalam Politik Bahasa Nasional 1. Jakarta: Balai Pustaka. Hlm. 13-25. 1976.

Kartono, Giri. "Kedudukan dan Fungsi Bahasa Asing di Indonesia" dalam Politik Bahasa Nasional 2. Jakarta: Balai Pustaka. Hlm. 121-130. 1984.

Retmono. "Pengajaran Bahasa Asing dalam Rangka Politik Bahasa Nasional" dalam Politik Bahasa Nasional 2. Jakarta: Balai Pustaka. Hlm. 131-142. 1984.

Sutami, Hermina. "Peningkatan Mutu Pengajaran Bahasa Asing NonInggris: Khususnya Bahasa Mandarin". Makalah disajikan pada Kongres Bahasa Indonesia VIII, 14-17 Oktober 2003. 2003.

. "Pengajaran Bahasa Mandarin yang Efektif dalam Menghadapi Era Globalisasi". Makalah pada Seminar Bahasa Tionghoa Problema Penguasaannya dan Perannya dalam Bisnis Internasional. Diselenggarakan oleh Program Studi Cina FIB UI, 22 Juni 2006. 2006.

. "Pembelajaran Bahasa Mandarin Sesudah Reformasi 1998 dalam Pendidikan Formal dan Nonformal di Jakarta, Khususnya Universitas Indonesia". Makalah dalam Seminar Mengukur Kualitas Pembelajaran Bahasa Mandarin di Indonesia, diselenggarakan oleh Konsorsium Kursus Bahasa Mandarin Direktorat Pembinaan Kursus dan Kelembagaan, Direktorat Jenderal Pendidikan Nonformal dan Informal, Departemen Pendidikan nasional dan Harian Indonesia. 2008.

. "A Syllabus for Mandarin in Indonesian High Schools". Makalah

disajikan dalam The First Annual International Symposium of Foreign Language 
Learning yang diselenggarakan oleh Seameo Regional Centre for Qitep Language, Jakarta 20 Oktober 2010. 2010.

Sutami, Hermina. "Rencana Strategis Pengajaran Bahasa Mandarin di Indonesia". Usulan diajukan kepada Wakil Menteri Pendidikan dan Kebudayaan. 2011.

Suryadinata, Leo. Dilema Minoritas Tionghoa. Jakarta: Grafiti. Press. 1984.

Tjahjadi, Lilysagita. "Pengajaran Bahasa Cina di Indonesia" makalah Seminar Internasional Pengajaran Bahasa dan Dinamika Budaya Asia di Asia. Diselenggarakan di Jakarta oleh FIB UI dan Hankuk University of Foreign Studies, 12 Januari 2006. 2006. 


\section{LAMPIRAN}

Surat Dra. Inny C. Haryono kepada Atase Kebudayaan RI di Beijing

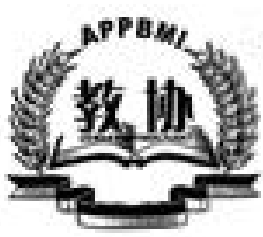

DEWAN PIMPINAN PUSAT

ASOSIASI PENDIDIK DAN PENGEMBANG BAHASA MANDARIN DIINDONESIA

印尼汉语教学促进协会

MITRA KERJA DITJEN PNFI KEMENTERIAN PENDIDIKAN NASIONAL R.I

Jakarta, 15 Juni 2012

No $\quad: 179 / D P P-A P P B M I / N I / 2012$

Perihal : Informasi tentang pengajaran bahasa Mandarin di Indonesia

Lampiran : berkas informasi

Kepada Yth.

Atase Pendidikan Kedutaan Besar

Republik Indonesia di RRC

Beijing

Dengan hormat,

- Terlebih dulu kami memperkenalkan diri, ibu Inny C. Haryono, saat ini menjabat sebagai Ketua Umum APPBMI, , mitra kerja DITJEN PAUDNI KEMDIKBUD, di bidang pengembangan dan peningkatan mutu pengajaran bahasa Mandarin di Indonesla. Sebelumnya dari tahun 2001 - 2010 menjabat sebagai Ketua Konsorsium Kursus Bahasa Mandarin Direktorat Pembinaan Kursus dan Kelembagaan DITJEN PNFI KEMDIKNAS (sekarang DITBINSUSLAT DITJEN PAUDNI KEMDIKBUD) disamping itu, saat ini kami juga menjabat sebagai Komisaris surat kabar berbahasa Mandarin HARIAN INDONESIA XINGZHOU di Jakarta (sejak terbit tahun 1966 menjabat Redaktur HARIAN INDONESIA MANDARIN $s / d$ tahun 2006). Latar belakang pribadi perlu kami sampaikan agar memahami mengapa sumber bahan informasi kami ambil dari pers berbahasa Mandarin, dan dari lingkungan pergaulan dengan komunitas Cina di Indonesia.

- Kami mengamati situasi pengajaran bahasa Mandarin di Indonesia karena disamping jabatan kami tersebut, kami juga berkedimpung di bidang pengajaran bahasa Mandarin, baik di Perguruan Tinggi (dosen FSUI dan FS UNSADA), dan mengelola lembaga kursus Mandarin tahun 1996 - 2006 di daerah Pancoran - Glodok Jakarta. Pengamatan ini terus kami laksanakan dari sejak diberikan ijin pengajaran, bahasa Mandarin bentuk kursus (1994) 
sampai era reformasi saat ini yang bahkan sudah menjangkau pengajaran tingkat TK s/d Perguruan Tinggi.

- Barangkali hasil pengamatan yang kami tuangkan dalam bentuk informasi dengan sedikit analisis terlampir, ada manfaatnya terutama mengacu kepada kebijakan Pemerintah Indonesia di bidang pengajaran bahasa Mandarin yang dalam hal ini menjadi tugas Kemdikbud.

- Atas perhatian diucapkan terima kasih.

Hormat kami,

Ketya Umum APPBMI,

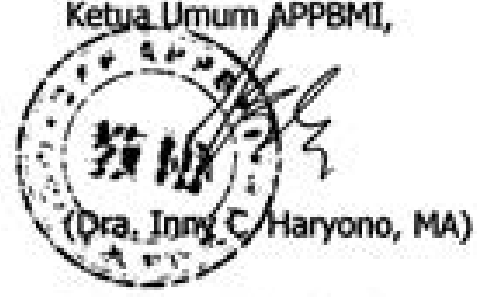

Tembusan Yh: (sebagal laporan)

1. Menteri Pendidikan dan Kebudayaan

2. Kashar LP2KB - BIN

3. Pertinggal 


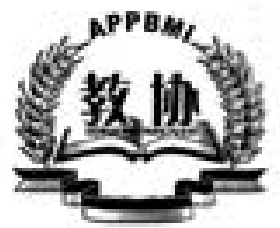

. MITRA KERJA DITJEN PNFI KEMENTERIAN PENDIDIKAN NASIONAL R.I

DEWAN PIMPINAN PUSAT

ASOSIASI PENDIDIK DAN PENGEMBANG BAHASA MANDARIN DIINDONESIA

印尼汉语教学促进协会

\section{PENGAJARAN BAHASA MANDARIN \\ DI INDONESIA ERA REFORMASI}

Perlu Kejelasan Arah dan Tujuan

Demi Kepentingan Bangsa dan Negara Indonesia

Inny C. Haryono

Ketua Umum APPBMI

\section{PENGANTAR}

- Seperti diketahui, pengajaran bahasa Mandarin di Indonesia sudah dimulai sejak perantau Cina berdatangan ke Indonesia. Adapun tujuan utamanya adalah untuk tetap melestarikan budaya dan bahasa Cina bagi keturunannya agar tetap berorientasi ke negara leluhurnya. Tujuan utama ini tetap berlangsung hingga saat ini, dengan dukungan penuh baik dari komunitas Cina Indonesia maupun dari Pemerintah Cina lewat Kedutaan Besar RRC di Indonesia. Hal ini dapat diamati dikalangan komunitas Cina Indonesia, baik di Jakarta maupun di daerah di Indonesia (mengikuti berita dari pers bahasa Mandarin di Indonesia)

- Dalam kurun waktu satu dasawarsa lebih, situasi pengajaran bahasa Mandarin di Indonesia semakin meluas, baik wilayah maupun tingkat pendidikan, yang menurut peraturan resmi diajarkan minimal tingkat Sekolah Menengah Tingkat Atas, tapi pada kenyataan bahkan sudah diajarkan di tingkat play - group dan Taman Kanak-Kanak (TK). Booming pendidikan bahasa Mandarin di Indonesia sebenarnya didominasi oleh lembaga pendidikan swasta, utamanya oleh kalangan Komunitas Cinasehingga nampak dengan jelas arah dan tujuan diperuntukkan bagi 
kalangan Cina (HUAZHU). Dukungan dana juga dari pengusaha Cina yang benar-benar bersedia bertindak sebagai donatur atau sponsor karena arah dan tujuannya untuk menjadikan generasinya berbahasa dan berbudaya Cina, tidak/kurang memahami kebijakan Pemerintah Indonesia yang menjadikan bahasa Mandarin sebagai bahasa asing.

- Artikel ini akan membahas masalah yang muncul dari pengajaran bahasa Mandarin di Indonesia, yang pada era Reformasi saat ini ternyata mengalami perubahan arah dan tujuan yang telah digariskan oleh Pemerintah, dalam hal ini Kementerian Pendidikan dan Kebudayaan. Penyimpangan arah dan tujuan ini terus berlangsung tanpa kendali, sehingga dikhawatirkan akan memunculkan hal-hal yang tidak menguntungkan, baik bagi bangsa dan negara, maupun bagi hubungan baik antar negara, Indonesia dan Cina.

\section{KETERKATTAN DENGAN NEGARA LELUHUR}

- Ada indikasi bahwa pengajaran bahasa Mandarin di Indonesia yang selama satu dasawarsa lebih ada kaitan dengan negeri leluhur Cina mengingat pelaksanaannya didominasi oleh komunitas Cina Indonesia. Dari beritaberita yang dimuat dalam pers berbahasa Mandarin di Indonesia mengindikasikan hal tersebut dengan selalu menitikberatkan siswa/peserta didik kalangan masyarakat Cina Indonesia (HUAZU), dan kurang pada anak bangsa lain. Komunitas Cina Indonesia dengan giat dan bersemangat mendirikan lembaga pendidikan bahasa Mandarin dari jenjang terendah play group sampai jenjang pendidikan Tinggi / college, universias.

- Dana dari para pengusaha mengalir ke usaha pengajaran bahasa Mandarin yang dikelola oleh komunitas Cina diseluruh Indonesia. Kurikulum diarahkan kepada bahasa dan budaya Cina, baik untuk persiapan penguasaan 
bahasanya maupun fisolofi leluhur Cina Di Zi Gui 'budi pekerti' leluhur Cina yang selalu ditebarkan di lembaga pendidikan maupun dalam seminarseminar yang diselenggarakan mereka.

- Disamping itu, dengan bantuan komunitas Cina pula diselenggarakan studi wisata ke Cina bagi pelajar yang sebagian besar merupakan siswa komunitas Cina.

- Saat ini Kominitas Cina bersemangat membentuk organisasi yang arah tujuan juga ke negeri leluhur dengan menghimpun ke dalam organisasi berdasarkan nama marga 'XING', berdasarkan asal daerah kampung halaman di Cina 'TONGXING', yang nampaknya sangat mencolok, dan nampak bersaing satu sama lain dengan menonjolkan tokoh pengusaha yang sukses. Pemunculan pada kegiatan yang sifatnya kurang signifikan dengan situasi negara kita.

\section{PERAN PEMERINTAH RRC}

1. - Terdapat perjanjian kerjasama antara Pemerintah Indonesia (Kementerian Pendidikan Nasional) dengan Pemerintah RRC (HANBAN) dalam pengajaran bahasa Mandarin di Indonesia, yang dituangkan dalam MOU kedua negara, tahun 2001. Bentuk kerjasama berupa pelaksanaan ujian Internasional bahasa Mandarin HSK di Indonesia. Pada awalnya untuk dewasa, sejak tahun 2007 di kembangkan ke anak muda atau YCT (Young Chinese Test). Pada awalnya baru dilaksanakan di 3 (tiga) kota : Jakarta, Bandung, dan Medan, kemudian saat ini di 8 kota. Pesertanya cukup banyak, terus bertambah dari tahun ke tahun, namun lebih ditekankan ke anak-anak (YCT), sedangkan peserta tingkat lanjut (advance), semakin berkurang disebabkan masih belum banyak mencapai tingkatan tersebut. 
Pelaksanaan ujian HSKYYCT, Diknas (waktu itu) menugaskan Konsorsium kursus Bahasa Mandarin yang bernaung dibawah Diknas (SK. DIRJEN PNFI), penulis menjabat sebagai ketua periode 2001 - 2004 dan 2004 2010.

- HANBAN juga menyelenggarakan pelatihan guru Mandarin di Indonesia, tetapi dalam bentuk massif, pesertanya berjumlah $200-400$, tanpa seleksi, tanpa evaluasi, semacam Seminar (tidak kualitatif), semua mendapat sertifikat, baik peserta yang mengikuti dengan seksama maupun yang tidak. Pelathan macam ini sudah terlaksana dari tahun 2001 s/d saat ini, baik di lakarta maupun di kota lain di Indonesia.

- Disamping pelaksanaan HSK/YCT dan pelatihan guru, HANBAN juga telah menyusun Buku Pelajaran Bahasa Mandarin untuk siswa SMU/SMK, akan tetapi ternyata materi tidak sesuai dengan kondisi siswa Indonesia.

- Mulai tahun 2004, HANBAN mengirim guru relawan bahasa Mandarin lulusan Program Studi Cina jenjang S1 ke sekolah di Indonesia. Setiap tahun pengiriman guru relawan ini dilaksanakan, sampai saat ini. Tahun 2009, HANBAN juga mengirim dosen untuk Perguruan Tinggi di Indonesia.

2. - QIAO BAN, lembaga resmi RRC 'Kantor Urusan Perantau' juga bekerjasama dengan Kemdikbud di bidang pengajaran Bahasa Mandarin di Indonesia, akan tetapi sebatas pelathan guru Mandarin di Indonesia. 'Kantor Urusan Perantau' ini lebih menekankan tugasnya membantu Komunitas Cina Indonesia dalam bidang pendidikan bahasa Mandarin dan budaya Cina, sesuai nama lembaganya 'Kantor Urusan Perantau'.

3. KONGZ XUEYUAN 'Institute Confucius', lembaga resmi Pemerintah RRC yang baru berdiri tahun 2007, bersama-sama HANBAN sebagai lembaga 
resmi Kementerian Pendidikan Cina, bertugas menyebarluaskan bahasa dan budaya Cina ke seluruh dunia, termasuk ke Indonesia.

4. Di samping itu, beberapa lembaga resmi lain juga sudah masuk ke Indoneisa, tenutama melaksanakan pelatihan guru Mandarin di Indonesia. Ada lembaga tingkat Perguruan Tinggi, ada pula lembaga tingkat Kota. BIEEC (Beijing International Education Exchange Center) dari kota Beijing bekerjasama dengan komunitas Cina Indonesia menyelenggarakan pelatihan guru Mandarin di Jakarta tahun 2011. Tahun 2012 rencananya bekerjasama dengan ASOSIASI PENDIDIK dan PENGEMBANG BAHASA MANDARIN di INDONESLA (APPBMI) menyelenggarakan pelatihan guru di Surabaya dan DI Yogyakarta bulan Agustu 2012.

5. - Perlu dilinformasikan pula bahwa disamping pengajaran bahasa Mandarin untuk sekolah, ternyata ada juga kegiatan kuliah jarak jauh (semacam Universitas Terbuka) yang dilaksanakan beberapa Universitas di Cina untuk peserta di Indonesia, baik jenjang Diploma Tiga (D3) maupun jenjang S1 dan S1. Universitas Jinan, Universitas Xiamen dan Universitas Hua Qiao. Ketiga Universitas ini telah meluluskan sekitar 1000 lebih Iulusan, akan tetapi jazahnya tidak diakui DIKTI.

\section{PERAN PEMERINTAH INDONESIA}

- Pemerintah Indonesia yang dalam hal ini Kemdikbud bertugas melaksanakan pengajaran bahasa Mandarin di Indonesia. Pada tahun 2004 DIKNAS menyelenggarakan Seminar membahas Prospek Kerjasama Teknik Indonesia - RRC (bidang Pendidikan), bekerjasama dengan BIRO KERJASAMA TEKNIK LUAR NEGERI SEKRETARIAT NEGARA. Pembahasannya komperehensif, dan mendetail yang perlu dipahami 
secara bersama oleh semua penyelenggara pendidikan yang akan bekerjasama dengan Pemerintah RRC.

- Pada Seminar tersebut dibahas tentang peningkatan kerjasama bidang pendidikan, baik oleh instansi pemerintah maupun swasta. Dalam kaitan ini, baik instansi Pemerintah maupun swasta telah berkembang pesat menjalin kerjasama, baik dalam hal memanfaatkan tenaga ahli dari Cina, maupun penyusunan bahan ajar dan kurikulum. Akan tetapi, baik kurikulum maupun bahan ajar yang sudah disusun ternyata harus selalu dievaluasi dan disesuaikan dengan kondisi siswa Indonesia. Pemanfaatan guru relawan juga harus ditinjau dan dievaluasi apakah sudah sesuai dengan metode pengajaran di Indonesia.

- Seminar tahun 2004 tersebut mengisyaratkan dan menjadi panduan dalam pelaksanaan kerjasama RI - RRC bidang pendidikan.

- Pemerintah yang dalam hal ini KEMDIKBUD memiliki beberapa DIRJEN yang menangani pengajaran bahasa Mandarin. Pada awalnya, karena pengajaran bahasa Mandarin. Pada awalnya, karena pengajaran bahasa Mandarin dilaksanakan oleh lembaga kursus (1994 - 2001), maka yang menangani adalah DIRJEN PLS / Non Formal Tahun 2001, DIRJEN DIKMENJUR / Kejuruan, tapi sejak tahun 2004 dilaksanakan di Sekolah Menengah Umum/ SMK.

- Saat ini KEMDIKBUD menangani pengajaran bahasa Mandarin untuk Sekolah Formal dan Nonformal dan Informal. Sekolah Formal mencakup SD, SMP, SMA s/d Perguruan Tinggi, Non Formal Informal mencakup lembaga kursus, privat, dan homeschooling. Begitu juga untuk kegiatan pelatihan guru, terbagi lagi menjadi guru sekolah formal dan guru lembaga Pendidikan Non Formal. 
- Terkotak-kotaknya bidang pendidikan di Kemdikbud ini menimbulkan kerumitan, terutama dalam hal pelatihan atau peningkatan mutu guru Mandarin, karena guru Mandarin sekaligus mengajar baik di sekolah formal maupun di lembaga kursus dan pelatihan. Untuk mengadakan pelatihan guru harus pula dipilah lagi apakah guru Mandarin sekolah Formal ataukah guru Mandarin Non Formal Informal, karena masingmasing ada DIRJEN sendiri. Dalam kenyataan di lapangan guru Mandarin mengajar di sekolah formal sekaligus juga mengajar di Lembaga kursus baik privat maupun pelatihan (in house training), metode pengajaran tidak jauh berbeda, materi juga tidak beda, malahan siswa di lembaga kursus jumlahnya dibatasi, lebih efektif. Terkotaknya institusi di Kemendikbud dirasakan agak membingungkan oleh HANBAN dalam hal kerjasama karena di Cina tidak ada pengajaran bahasa Mandarin bentuk nonformal.

- Dalam pelaksanaan di lapangan, baik pengajaran di sekolah Formal dan Non Formal Informal, pelatihan guru, pengelolaan guru relawan dari RRC semua diserahkan kepada organisasi masyarakat/komunitas Cina BADAN KOORDINASI PENDIDIKAN BAHASA MANDARIN (BAKORPEN). Organisasi ini sejak berdiri Tahun 2004 telah menjadi tumpuan atau motornya penyelenggaraan pengajaran bahasa Mandarin di seluruh Indonesia dan di semua jenjang pendidikan dari TK - PT. Wewenang yang besar dan kuat ini mendapat dukungan dari komunitas Cina, terutama para pengusaha besar seperti The Ning King, dan lainnya. Dengan adanya kewenangan macam ini, Pemerintah RRC dalam hal ini HANBAN, QIAO BAN, dan institusi Pemerintah RRC lainnya dan dukungan penuh dari Kedutaan Besar RRC di Indonesia. 
- Banyak pakar bahasa Mandarin di Indonesia lulusan Perguruan Tinggi di Indonesia akan tetapi sayang Kemdikbud tidak berminat untuk memanfaatkan mereka, akan tetapi sebaliknya menggunakan organisasi masyarakat Komunitas Cina yang kepakaran di bidang ini masih dipertanyakan. BAKORPEN nampaknya memanfaatkan kelemahan Kemdikbud untuk melaksanakan misi orientasi ke negeri leluhur dan pengajaran bahasa Mandarin untuk komunitas Cina (HUAZHU).

- Kerjasama antar negara sudah nampak dilaksanakan tidak sesuai arah dan tujuan yang sebenarnya, yang menjadikan bahasa Mandarin sebagai bahasa asing, sebagai alat komunikasi di tempat kerja, akan tetapi malahan diajarkan di tingkat TK, SD.

- Ketua BAKORPEN, Arifin Zain yang telah sukses mengemban pendidikan bahasa Mandarin di Indonesia telah mendapat piagam penghargaan dari Pemerintah RRC, dalam hal ini 'Kantor Urusan Perantau' 'QIAU BAN' pada Kongres ke-5 pengajaran bahasa Mandarin Internasional yang diselenggarakan tahun 2007 di Qingdao. Ini membuktikan bahwa misi pengajaran bahasa Mandarin untuk masyarakat Cina Indonesia berhasil. Mendapat dukungan penuh dari komunitas Cina Indonesia dan dukungan penuh dari kedutaan Besar RRC di Indonesia.

- Seperti diketahui, Kemdikbud memiliki KONSORSIUM KURSUS BAHASA MANDARIN di DITJEN PNFI (sekarang DITEEN PAUDNI). Tapi sayang, dengan adanya peng-kotakan di Kemdikbud, peranan KONSORSIUM tidak sebesar dan sekuat BAKORPEN. Anggota KONSORSIUM adalah pakar dari Perguruan Tinggi, pendidik, pengelola lembaga kursus, pemerhati, dan pengguna jasa lulusan (USERS), akan tetapi peranannya dikecilkan, sebatas pendidikan Non Formal, itupun sering tidak dilibatkan dalam posisi 'decision maker' pengajaran bahasa Mandarin. 
- Saat ini sudah terbentuk organisasi profesi APPBMI dan telah melahirkan LSKBMI, namun tetap di DITJEN PAUDNI Non Formal. Organisasi profesi APPBMI didirikan karena panggilan Undang-undang atau Permendiknas No. 7 tahun 2008 dengan tujuan melahirkan LSKBMI (LEMBAGA SERTIFIKASI BAHASA MANDARIN INDONESIA) yang akan bertugas menyelenggarakan uji kompetensi bahasa Mandarin di Indonesia, utamanya untuk siswa kursus sudah dikukuhkan oleh DIRJEN PAUDNI tahun 2010 APPBMI berdiri tahun 2009.

- Perlu ditambahkan bahwa organisasi non komunitas Cina akan sulit memperoleh dukungan komunitas Cina di Indonesia sepanjang orientasi pengajaran bahasa Mandarin tidak ke negara leluhur Cina. Inilah kenyataan yang terlihat di Indonesia.

\section{SEKOLAH TIGA BAHASA}

- Komunitas Cina Indonesia senang dan sedang booming menyelenggarakan Sekolah Tiga Bahasa (San YU XUE XIAO), dari tingkat TK s/d Sekolah Menengah Atas. Sekolah Tiga Bahasa apabila diperhatikan lebih mengutamakan bahasa asing : Mandarin dan Inggris, sedangkan bahasa Indonesia sebagai bahasa Negara kurang begitu diutamakan. Hal ini nampak sewaktu pelaksanaan ujian Internasional bahasa Mandarin untuk remaja (YCT), anak-anak peserta ujian lebih lancar bicara Mandarin dan Inggris, dan tidak bicara bahasa Indonesia. Apakah KEMDIKBUD belum melaksanakan evaluasi terhadap sekolah macam ini ? 


\section{KESIMPULAN DAN SARAN}

1. Pengajaran bahasa Mandarin di Indonesia dalam kurun waktu satu dasawarsa lebih masih belum sesual sasaran dan tujuan, yaitu sesuai Undang-undang menyatakan bahasa Mandarin sebagai bahasa asing dan berfungsi sebagai alat komunikasi, bukan sebagai bahasa ibu yang berorentasi ke negara leluhur Cina. Ini berlaku untuk semua warga bangsa Indonesia, termasuk WNI Komunitas Cina.

2. Realisasi Perjanjian kerjasama $G$ to $G$ atau dua negara Indonesia - Cina di bidang pengajaran bahasa Mandarin tidak seharusnya dimanfaatkan oleh Komunitas Cina untuk siswa Komunitas Cina (HUA ZHU) yang saat ini secara kasat mata terlihat dimana-mana. Apabila hal ini tidak segera diluruskan arah dan tujuan sesuai SISDIKNAS di khawatirkan akan berdampak negatif di dalam masyarakat yang mendambakan kedamaian dan harmoni.

3. KEMOIKBUD sudah saatnya memanfaatkan pakar bahasa Mandarin lulusan Perguruan Tingi untuk dilibatkan dalam menangani penyelenggaraan pengajaran bahasa Mandarin di Indonesia, agar sesuai dengan kebijakan Pemerintah Indonesia. Satu dasawarsa lebih penanganan pengajaran bahasa Mandarin di Indonesia sudah saatnya memerlukan evaluasi menyeluruh terhadap penyelenggaraannya.

4. Selama ini terdapat kegiatan belajara jarak jauh bahasa Mandarin jenjang D3, S1, dan S2, yang dikelola oleh Komunitas Cina dengan Perguruan Tinggi di Cina, yang ternyata ijazahnya tidak diakui oleh DIKTL. Apakah hal ini akan terus dibiarkan oleh KEMDIKBUD, apakah memang sudah ada perangkat peraturannya ?

5. Penyusunan buku pelajaran Bahasa Mandarin oleh HANBAN untuk SMU/SMK, apakah sudah melewati perijinan Pusat Perbukuan KEMDIKBUD? 
Ternyata buku tersebut banyak kekurangannya sehingga ditolak untuk digunakan.

6. Guru relawan yang berbondong-bondong ke Indonesia apakah sudah diberikan pelatihan untuk mengajar di Indonesia, karena ada keluhan masyarakat bahwa cara mengajar mereka sangat keras terhadap murid Indonesia. Perlu diadakan evaluasi oleh KEMDIKBUD. Ada info sebagian guru relawan tidak kembali ke Cina.

7. Pelatihan guru yang dilaksanakan oleh lembaga resmi RRC bekerjasama dengan komunitas Cina Indonesia ternyata tidak efisien dan tidak efektif. Dengan jumlah peserta ratusan orang dan dalam waktu relatif singkat, tidak kena sasaran, karena semua peserta mendapat sertifikat yang belum tentu memperoleh kualifikasi. Pelatihan dilaksanakan hanya untuk mengejar target memperoleh pengakuan dari lembaga resmi RRC. Perlu dievaluasi

8. Saat ini sedang ramai membahas sertifikasi guru di Indonesia sebagai pengakuan atau standard profesi guru. Bagaimana dengan guru bahasa Mandarin, slapa yang berhak memberikan sertifikasi guru Mandarin di Indonesia ? Ini perlu dipertanyakan karena saat ini belum ada standarisasi untuk guru Mandarin di Indonesia, baik profesi maupun kompetensi bahasa Mandarin. Apakah semuanya akan diserahkan kepada Pemerintah Cina ? Dimana posisi kita Indonesia yang lebih memahami kondisi negara kita. Siapa yang memikirkan masalah ini ?

Jakarta, 15 Juni 2012 